\title{
NOTAS SOBRE JUDAÍSMO Y BIOÉTICA
}

\author{
Ana María Tapia-Adler*
}

Resumen: El presente artículo revisa algunos temas tradicionales de bioética desde la perspectiva del Judaísmo, refiere respuestas desde las fuentes originales, sus sucesivas exégesis y la legislación judía (Halajá), y revela la relación entre ciencia, fe y defensa de la vida en esta visión religiosa.

Palabras clave: bioética, Judaísmo, halajá, clonación, eutanasia, responsa, takaná

\section{NOTES ABOUT JUDAISM AND BIOETHICS}

Abstract: The present article reviews some traditional bioethical topics from Jewish perspective, it gives answers derived from original sources, their subsequent exegesis and from Jewish legislation (Halajá), and it unveils relations among science, faith and defense of life according to this religious view.

Key words: bioethics, Judaism, halajá, cloning, euthanasia, response, takaná

\section{NOTAS SOBRE JUDAÍSMO E BIOÉTICA}

Resumo: O presente artigo revisa alguns temas tradicionais de bioética a partir da perspectiva do Judaísmo, em busca de respostas, com base nas fontes originais, nas sucessivas exegeses e na legislação judaica (Halajá), e revela a relação entre ciência, fé e defesa da vida nessa visão religiosa.

Palavras-chave: bioética; judaísmo, halajá, clonagem, eutanásia, responsabilidade, takaná

* Licenciada en Filosofía con Mención en Lengua y Cultura Hebrea. Centro de Estudios Judaicos, Facultad de Filosofía y Humanidades, Universidad de Chile, Chile

Correspondencia: amta@uchile.cl 


\section{Introducción}

El presente artículo pretende introducir al lector en ciertos tópicos de bioética percibidos desde la perspectiva judaica. Se parte de la base que quienes tienen acceso a esta literatura poseen ya conocimientos acerca del Judaísmo, en tanto forma de vida y el modo como este regula la existencia del grupo desde el nacimiento hasta la muerte, a través de los preceptos señalados en la Torá1.

No obstante lo anterior, sí parece pertinente e importante detenerse en el concepto de "fuentes judías", las que abarcan tanto la Torá escrita (Torá shebijtav) ${ }^{2}$ como la Torá oral (Torá shebealpée) ${ }^{3}$. Debido a que la primera ha sido escrita en un lenguaje sucinto, ha sido necesario que, a través de las diversas épocas, se efectúe un trabajo de exégesis que permita su aplicación. Por ejemplo: "Guarda y santifica el día Shabat como te ha mandado el Señor tu Dios. Seis días trabajarás y harás obras; pero el séptimo día es descanso para el Señor tu Dios: no harás en él trabajo alguno ni tú, ni tu hijo, ni tu siervo, ni tu sierva, ni el extranjero que vive contigo..." ${ }^{\prime}$. Sin embargo: ¿qué significa "guardar el sábado"? ¿En qué sentido hay que entender el término "trabajo"?

De hecho, en la Torá no se encuentra expresada claramente la forma de observar el sábado y, respecto de "trabajo", en el texto se mencionan dos actividades: encender fuego y partir leña ${ }^{5}$. Empero, el judío ortodoxo no realiza ningún tipo de trabajo en Shabbat. Quien quiera saber de qué modo se debe "guardar" u "observar" el sábado y qué trabajos no están permitidos debe necesariamente recurrir al Talmud.

No es de extrañar entonces que, a través de los siglos, haya existido en el Judaísmo un proceso interpretativo basado, en su origen, en la transmisión oral, realizada de generación en generación. La compilación de esta "sabiduría" se conoce con el nombre de Ley o Torá oral (Torá shebealpe) y su desarrollo parte -de acuerdo con la tradición- desde el momento mismo de la entrega o revelación de la Torá escrita (Torá shebijtav).

1 Etimológicamente, el término "Torá" deriva de la raíz hebrea yrh, enseñar, y sobre la base de esta enseñanza se ha moldeado el "modo de ser judaico", enmarcado dentro de la observancia de los preceptos (mitzvot).

2 Se refiere a los cinco primeros libros de la Biblia, conocidos como Pentateuco.

3 La Torá shebealpé corresponde al Talmud.

4 Deuteronomio 5, 12 y ss.

5 Éxodo 35,3.
El primer Código de Ley oral estructurado se conoce con el nombre de Mishná ${ }^{6}$, texto que sirvió de base para posteriores discusiones y precisiones y para sentar jurisprudencia. Pero la labor exegética no se detuvo allí y después de compilada la Mishná se compendia o codifica el texto conocido como Guemará ${ }^{7}$. La unión de ambos dio como resultado el Talmud ${ }^{8}$.

El proceso de unificación se realizó paralelamente en Israel y en Babilonia, razón por la cual existen dos versiones del Talmud: el Jerosolimitano y el Babilónico. Éstos, junto con la Torá, forman la gran base sobre la cual se desarrolló la Halajá ${ }^{9}$ (el Derecho, Ley o Jurisprudencia judía).

El Talmud posee un sistema de interpretación y una lógica no asequible al lector común. Para entenderlo es necesario un largo proceso de estudio y mucho conocimiento. Por esa razón, a partir del siglo X d.C. se procedió a la codificación de las leyes de acuerdo con un orden temático. Entre las codificaciones más conocidas y utilizadas destacan la obra de Maimónides "Mishné Tora"10 "Arba'á Turim"11, del rabino Yaacov ben Asher, y la de Yosef Caro, "Shulján Aruj" 12 , obra complementada tiempo después por el rabí Moshé Isserles.

No obstante, como la Halajá debe dar respuesta a las interrogantes y dilemas que se presentan en el tiempo, el proceso de exégesis no se ha detenido: sigue vigente, tomando en cuenta la jurisprudencia sentada en el correr de las épocas y los códigos mencionados, fruto de la sistematización del Talmud. Hay que agregar -con posterioridad- la literatura de Responsa (Sheelot

6 De la raíz hebrea shaná, repetir. La Mishná es la repetición de la "enseñanza" y en seis tratados o secciones compila un corpus de leyes transmitidas a través de la tradición oral. Data del siglo II y es obra de Yehudá HaNasí.

7 De la raíz hebrea gmar, que significa "concluir, terminar", en el sentido de "completar", que es lo que justamente hace la Guemará, considerada como el comentario de la Mishná.

8 De la raíz hebrea limed, enseñar. Es importante destacar que lo expresado acá es una simplificación de lo que ha sido la composición del Talmud, que es mucho más larga y complicada.

9 Del término hebreo holej, caminar, transitar. La Halajá es pues el sendero señalado por la tradición, por el cual debe transitar todo judío.

10 Mishné Torá es el nombre de una de las obras de Rambam (Maimónides), conocida también como "Leyes de los Fundamentos de la Tora" (Hiljot iesodé haTorá).

11 Arba'a Turim, literalmente "Los cuatro pilares", es uno de los primeros códigos de jurisprudencia judía.

12 El Shulján Aruj es mucho más que un compendio de leyes, como su nombre lo indica. Significa literalmente "la mesa puesta" y constituye un manual prolijamente ordenado por temas que permite al judío saber qué es lo que corresponde hacer en el momento y lugar adecuados. 
Utshubot) ${ }^{13}$, que contiene las respuestas dadas por sabios prestigiados a consultas acerca de la casuística legal. Los códigos y la literatura de Responsa devienen en parte esencial de la legislación judía y son estas últimas las que facilitan la aplicación de la Halajá.

Otro punto importante es que, siendo tan amplias las fuentes y no existiendo un cuerpo legislativo único al interior del Judaísmo -como en la antigüedad lo constituyó el Sanhedrin- ${ }^{14}$, no encontraremos "la respuesta" del Judaísmo" a determinados problemas. Existen situaciones como la muerte asistida (eutanasia), la clonación, los trasplantes de órganos, la concepción in vitro y la manipulación genética, entre otros, para las cuales no se encuentra una jurisprudencia rabínica (talmúdica). Es un desafío planteado a la Halajá y a los rabinos especializados en legislación judía (poskim), quienes deben analizar cada caso en su individualidad, tomando en cuenta factores positivos y negativos, y que, para encontrar respuestas, escudrińan las fuentes en busca de analogías ${ }^{15}$.

Lo anterior hace que no haya una respuesta única a un mismo problema. Hay ocasiones en que varios rabinos coincidirán y otras en las que diferirán en sus posturas.

La información que se entrega en este artículo está basada en lecturas de las fuentes judías, a la luz de la interpretación realizada por diversos expertos; por lo tanto, veremos reflejadas aquí distintas opiniones.

13 Sheelot utshuvot, literalmente "preguntas y respuestas".

14 Sanhedrin corresponde a la asamblea de hombres notables (sabios) que había en cada una de la ciudades de Israel en la antigüedad. Existía también el Gran Sanhedrin, equivalente al Tribunal o Corte Suprema, con asiento en la ciudad de Jerusalén y presidida por el Gran Sacerdote (Kohen Gadol).

15 Recuerdo que, formando parte del grupo de Ética y Religión de la Vicerrectoría Académica de la Universidad de Chile, aprovechando uno de los viajes a Israel pedí una reunión con el Dr. Or, en ese entonces Director del Departamento de Trasplante de Médula Ósea del Hospital Hadassah, en Jerusalén, porque estaba interesada en saber de qué modo se congeniaba el tema de los trasplantes con la Halajá, dado que era algo total y absolutamente actual y no considerado en las fuentes. Debido a sus urgentes actividades médicas, finalmente todo se transformó en una "conversación de pasillo". En esos minutos me explicó que cuando una madre no tiene leche para amamantar a su hijo recién nacido se busca una nodriza para que lo haga (hay algunas situaciones mencionadas en el Tanaj, Antiguo Testamento). Del mismo modo como la leche es indispensable para la vida del bebé lo es la médula ósea para cualquier ser humano. En este caso, la médula sería a la persona lo que la leche al infante.

\section{La bioética y el Judaísmo}

No es de extrañar que la mayoría de las personas vean al Judaísmo sólo como una religión más y piensen, equivocadamente, como ocurrió hace siglos con la Iglesia Católica Apostólica Romana, que también en el Judaísmo "ciencia y religión" no "van de la mano". Pero eso no es así, ya que en el Judaísmo, desde antaño, el conocimiento científico fue visto como una ayuda en la aplicación de ciertas normas de la Halajá (jurisprudencia judía).

Por ejemplo:

- El Yom Kippur (día del perdón) es un día de ayuno riguroso y obligatorio. La ciencia médica puede determinar si un enfermo debe comer o no durante este día, como asimismo puede también resolver problemas de vida o muerte en relación con el parto o los trasplantes de órganos.

- El conocimiento de la astronomía hizo posible realizar los cálculos necesarios para determinar los años bisiestos y fijar el calendario judío con las fechas correctas para la celebración de las festividades.

Como estos, son muchos los ejemplos que pueden mencionarse para revelar la importante relación entre ciencia y religión en la fijación de dictámenes balájicos.

Es menester percibir a la ciencia como aquella actividad que entrega al hombre conocimiento y herramientas tecnológicas para hacer de su vida algo mejor y a la Torá como la que proporciona las pautas éticas acerca de cómo deben ser utilizadas dichas herramientas. Así pues, ciencia y Torá deben ir juntas. En el Judaísmo, el conocimiento por el conocimiento y la experimentación sólo por alcanzar mayor conocimiento no son aceptables si no van acompañados de un comportamiento ético que implique hacerse responsable de acciones y descubrimientos, y que estos vayan encaminados a mejorar la vida del hombre ${ }^{16}$.

\section{"Observaréis mis estatutos y mis ordenanzas destinadas a hacer vivir al hombre"}

En este sentido, la ciencia médica, destinada a mejorar la calidad de vida de los seres humanos y a curar -en la medida de sus posibilidades- las enfermedades que

16 Esta es una de las primeras enseñanzas que podemos inferir o deducir de la Torá. Cfr. Génesis 2,3.

17 Levítico 18,5. 
éstos puedan padecer, es una ciencia que conlleva el comportamiento ético de aquellos hombres que la practican. Numerosos problemas relacionados con el inicio y el fin de la vida están bajo la supervisión de los comités de ética, los cuales cuentan entre sus miembros no sólo a médicos, sino también a expertos en asuntos religiosos (en nuestro caso, en Halajá) que deben lidiar con todo lo que la medicina y la relación médico-paciente implica desde una perspectiva ética. Además, procurar que no se lesione lo que la perspectiva religiosa señala y que determina lo que puede o no hacerse desde el punto de vista de la Halajá. Habrá oportunidades en que los dictámenes halájicos podrán no concordar con ciertas prácticas médicas.

Si uno busca en el Talmud, también es posible encontrar tratamientos y medicinas que se prescriben en ciertos casos, pero que no se pueden usar en los pacientes, porque muchas veces no es posible identificar correctamente las dosis exactas ni las instrucciones para administrarlas(1). Lo correcto, entonces, es la utilización de los métodos modernos en beneficio del paciente.

En este punto, resulta importante destacar la gran responsabilidad que recae en los hombros del médico, quien está obligado -aun cuando el paciente no lo admita- a realizar todo lo posible con el fin de que este continúe con vida, porque no hacerlo es equivale a "derramar sangre" (2).

Como señalamos, los considerables avances de la ciencia y la tecnología médica parecieran poner en jaque a la Halajá, que debe plantearse importantes preguntas, como por ejemplo: ¿en qué momento puede considerarse muerta una persona? La fuente básica de consulta la constituye la Torá y el Talmud. El texto bíblico es explícito: una persona muere cuando deja de respirar. De ser así, los trasplantes no serían viables, dado que el órgano a trasplantar se dañaría. Entonces, ¿qué hacer? En estos casos los médicos utilizan el criterio de "muerte clínica”, esto es, cuando cesa la actividad cerebral, pero en esos casos el sujeto aún respira y su corazón late. ¿Es halájicamente aceptable este criterio? ¿Cuál es la respuesta de la Halajá ante este y otros desafíos que le presentan los nuevos métodos y descubrimientos médicos?

Hay quienes aceptan el criterio de "muerte cerebral" adoptado por el Comité de la Escuela de Medicina de
Harvard en 1968(2); otros, en cambio, lo han rechazado rotundamente ${ }^{18}$.

Insistimos en que es necesario comprender que la $\mathrm{Ha}$ lajá regula toda la vida judía, por lo tanto, se esperan de ella respuestas que permitan vivir de acuerdo con los preceptos en las diferentes épocas. Por eso existe la literatura de Responsa, la cual muestra diferentes variantes, ya que no siempre hay una respuesta única.

El Judaísmo concibe al hombre creado a imagen de Dios, por lo que la bioética judía se basa principalmente en el respeto al ser humano, "tanto durante esta breve vida como en la eterna” (3). Por eso no es de extrañar que toda la normativa judaica esté dirigida a que el hombre viva de acuerdo con ella y no para morir por ella. Entonces, cualquier precepto puede suspenderse cuando entra en conflicto con los intereses de la vida humana(1:145).

Puesto que en el Judaísmo el valor de la vida humana está más allá de toda consideración, existe una oposición incondicional hacia la eutanasia como también hacia el aborto. Aún más, el médico está obligado a hacer lo posible para velar por la salud del paciente, incluso a pesar del enfermo, ya que no proporcionar tratamiento médico adecuado es equivalente, como ya dijimos, a "derramar sangre".

Se entiende que debe hacerlo "incluso a pesar del enfermo", porque existe la prohibición de entregar voluntariamente la vida. Eso indica que, de acuerdo con la ley judía, no se necesita el consentimiento del paciente para efectuar una operación de urgencia. Es más, el médico debe incluso correr el riesgo de ser demandado por el eventual incumplimiento de su deber(4). Por otro lado, cualquier error de juicio por parte del facultativo le expone a convertirse inadvertidamente en homicida, lo que implica la enorme responsabilidad al escoger un tratamiento o acción a aplicar $(1: 146)^{19}$.

La única forma de asegurar que ello no ocurra es teniendo cuidado de aplicar lo que se considera un "procedimiento pertinente". De acuerdo con el Rambam ${ }^{20}$, este

18 Jacob cita entre los que "rechazan vigorosamente" este concepto a David Bleich (Hapardes, Tevet 5737) y Jacob Levy (Hadarom, Nisan 5731, Tishri 5730, Noam, 5.30).

19 Sin embargo, en Abraham S. The Comprehensive Guide to Medical Halachah (1996) puede leerse lo siguiente: "si el paciente muere como resultado del genuino error del médico, él no es considerado culpable” (pág. 146).

20 Rabí Moshé ben Maimon, más conocido como Maimónides, médico, teólogo y filósofo que vivió en el siglo XII y fue una autoridad en materia de Halajá. 
procedimiento es aquel que ha demostrado su eficacia y que procede como deducción de las teorías físicas generalmente aceptadas. De modo que incluso a un paciente que sufre de una enfermedad fatal puede administrársele un tratamiento que si falla puede producirle la muerte, pero si es exitoso puede prolongarle la vida.

En la actualidad, los médicos se ven sometidos a procesos y demandas por las denominadas "malas prácticas". No resultaría extraño entonces que un galeno pudiera negarse a aplicar un tratamiento riesgoso; sin embargo, acorde con lo que señalan algunos autores, ello no podría ocurrir en el ámbito judaico, por el principio establecido por la legislación judía que establece que: "La Torá ha concedido permiso al médico autorizado para sanar, y se trata de un mandamiento incluido en el que ordena salvar la vida. Aquel que se rehúse a sanar está derramando sangre, incluso si hay otros médicos disponibles"(4:466). Lo anterior se basa en lo estipulado en el texto de Levítico: "no te quedarás impasible ante la sangre de tu prójimo"21.

Si seguimos el raciocinio de Jacobovitz, cuando se refiere a los diez principios básicos que deben regular los experimentos médicos en seres humanos, debería autorizarse toda posibilidad de salvar una vida, aun cuando no se tenga certeza de su preservación. Por eso, en casos desesperados, podrían aplicarse también tratamientos o medicaciones experimentales(4:459-460). Incluso estaría permitido tomar medidas que conlleven un riesgo inmediato a condición de evitar una muerte inminente, y también administrar tratamientos de valor dudoso o experimental si no se conocen métodos más seguros o no se dispone de ellos(4:460).

Algunos pacientes son conectados a máquinas que le permiten mantener algunas funciones del cuerpo. Ello conlleva un problema cuando se discute la posibilidad de desconexión del enfermo de las máquinas de las que depende.

En una entrevista realizada por David B. Green al rabino Dr. Mordejai Halperin, para el periódico The Jerusalem Report ${ }^{22}$, el rabino señaló que hay tres condiciones importantes que según la Ley Judía se deben cumplir para retirarle el apoyo a un paciente: "Primeramente, el paciente debe sufrir una enfermedad terminal, lo que se define como que él o ella morirán

21 Levítico 19,16

22 Artículo publicado en Chile en La Palabra Israelita del 15 de abril de 2005. Traducción de Eva Chechelnitzky. dentro de seis meses, más allá de lo cual es imposible hacer predicciones confiables; en segundo lugar, el individuo debe estar sufriendo terriblemente y, tercero, sabemos - porque el paciente lo ha dicho así- o estamos en posición de suponer que el paciente no desea que se le prolongue su vida. Si cualquiera de estas condiciones está ausente, entonces no se nos permite retirarle la ayuda médica”.

El periodista pregunta, a su vez: "Cuando usted dice 'ayuda médica', ¿qué incluye esto?” Halperin responde: "Le diré qué es lo que no se puede retirar bajo ninguna circunstancia según la Ley Judía. El paciente no puede ser privado de oxígeno, eso constituiría sofocación; el paciente no puede ser desconectado de ninguna inyección intravenosa, eso sería lo mismo que privarlo de agua, y no podemos dejar de alimentarlo, porque eso equivale a dejarlo morir de hambre”. Así pues, de no mediar estas condiciones, el acto de desconexión equivaldría a asesinato o, en el mejor de los casos, a suicidio asistido. Ninguno de los dos está permitido por la Halajá. Puede ocurrir sí que una persona gravemente enferma cometa suicidio, lo cual sigue sin ser aceptado halájicamente, pero -dice Halperin- "es un acto que puede ser comprendido, aun cuando no es aceptable", y lo dice porque, en nuestros días, el manejo del dolor es algo total y absolutamente controlable con aplicaciones de morfina, por lo que una actitud tal no es concebible sino en un momento de total desesperación.

Entonces, una persona enferma que ha sido "conectada" a determinadas máquinas para mantenerla con vida no puede ser desconectada porque ese acto equivaldría a asesinato. Pero, si ella lo pide, puede no ser conectada a algún tipo de máquina que le prolongue artificialmente la vida, salvo aquellas que ya han sido mencionadas por el rabino Halperin en la entrevista mencionada.

\section{"Quien destruye una vida, es como si destruyera todo un mundo y quien salva una vida, es como si hubiera salvado un mundo entero" 3}

Se deduce con claridad que la eutanasia, sea esta pasiva o activa, es un acto que el médico judío debe evitar completamente, puesto que sólo Dios puede dictaminar cuándo una vida debe terminar.

Otro asunto importante, desde la perspectiva bioética, dice relación con los trasplantes de órganos, ya que

23 Talmud, Sanedrín 37ª. 
extraer de una persona viva el corazón o cualquier otro órgano vital es considerado asesinato $(5)^{24}$. Las preguntas que se plantean en este caso son variadas: ¿qué es la muerte? ¿Quién debería definirla? ¿Cuándo puede considerarse muerta una persona?

Se considera muerta a una persona cuando hay suspensión completa de las funciones biológicas y el cuerpo no puede ya ser restaurado a su funcionamiento como organismo, aunque se perciban espasmos musculares en las extremidades. Ello coincide con el punto de vista médico, según el cual la muerte es el cese de vida, el cese de existir, definido como un paro total de la circulación de la sangre y un cese de las funciones vitales, como respiración, pulso, etc. En el caso de trasplantes, se utiliza el criterio de "muerte cerebral" que, como hemos visto, es aceptado por algunos expertos en Halajá y rechazado por otros. De todos modos, hay opiniones que señalan que, incluso después de declarada la muerte cerebral, deberían realizarse exámenes complementarios para estar seguros del diagnóstico(1:188).

La donación de órganos de una persona viva a otra está permitida siempre y cuando ello no signifique un daño permanente del donante(1:187).

¿Qué sucede cuando dos personas, en iguales condiciones, requieren un trasplante de rińón y hay sólo un donante cuyo órgano cumple con las características que ambos pacientes necesitan? ¿A quién se elige? ¿Quién determina la prioridad de supervivencia y qué derecho le asiste para efectuar dicha elección?(5:467). Este problema se presenta no sólo en el ámbito judaico sino en todo código religioso y hay que saber dar respuesta a ello. En esta clase de casos los comités de ética tienen una gran responsabilidad.

\section{"Y los bendijo Dios, y les dijo: fructificady multiplicaos, llenad la tierra y sojuzgadla..." "25}

En la normativa bíblica, el primero de los preceptos positivos se relaciona con procreación (tener hijos), lo que indicaría que el modelo deseable es el de procrea-

24 En la página 467 del mismo artículo, en relación con 'las prioridades', seńala que esta pregunta, presentada de ese modo, tiene un aspecto diferente y encuentra muchos precedentes. "En términos generales, la Mishná dictamina que la erudición en la Torá y los hechos meritorios le conceden prioridad a uno, puesto que sirven a las necesidades fundamentales de la sociedad". Esa es una opinión, ciertamente puede haber otras.

25 Génesis 1, 28. dores y progenie, en otras palabras, el modelo deseable es la familia.

Cuando una pareja no puede procrear, la ciencia médica provee diversos métodos que permiten la concreción del anhelo de tener hijos. ¿Cuál es la posición de la Halajá? Veamos a continuación algunas de las posibilidades que se le presentan a una pareja.

\section{Inseminación artificial}

La inseminación artificial presenta complicaciones desde el punto de vista de la Halajá cuando el donante no es el marido. La recomendación es que este proceso sea usado sólo después de que la pareja intente tener hijos durante un período de dos a cinco ańos por lo menos, incluso mediante otras opciones de fertilización, pues lo óptimo y esperable es que el donante sea el marido y que el semen utilizado sea el emanado después de realizada la $m i k v e^{26}$. Un problema adicional se presenta con el semen no utilizado, ya que hay prohibición de derramar el semen en vano, pero en este caso puntual, dado los fines que persigue, se considera al semen restante del mismo modo que cuando se ha llevado a cabo un intercurso sexual entre la pareja.

\section{Fertilización in vitro}

Es aceptada en los casos en que el marido produce muy pocos espermatozoides para poder embarazar a su mujer, o que la mujer presente una obstrucción de las trompas y no pueda pasar libremente el óvulo del ovario al útero. Las autoridades rabínicas aprobaron la fertilización in vitro del óvulo de la mujer con el esperma del marido y el subsecuente reimplante del óvulo fertilizado o el pequeño embrión en la matriz de la misma mujer. No se permite la utilización ni del semen ni del óvulo de otras personas.

Pudiera suceder también que en este proceso de implantación de varios embriones se produzca una preńez múltiple. En casos especiales, estaría permitido que uno de los fetos fuera abortado con el fin de que los otros pudieren desarrollarse normalmente(1:222).

26 Baño ritual de inmersión con propósito de purificación. A él también debe recurrir toda mujer después de concluido su período menstrual y durante el tiempo que este dura no debe haber contacto sexual entre la pareja. Está relacionado con el precepto de Taharatha-mishpajá (pureza familiar), que se logra cumpliendo con las leyes de la nidá (período de separación) y la Mikve (baño ritual). 


\section{Contracepción}

Pudiera suceder que el embarazo produzca riesgo de muerte en una mujer y médicamente sea necesaria la contracepción. Existe la posibilidad de que, analizada esa situación particular de la persona, le sea permitido el uso de un anticonceptivo oral, caso en el cual deberá someterse a sí misma a constantes revisiones. Los métodos de contracepción también presentan problemas de índole halájica que deben ser resueltos por expertos en el tema(1:220).

\section{El aborto}

Existen al respecto criterios que emanan de la Torá y el Talmud, y la decisión de concretarlo se estudia también caso a caso. Se parte del supuesto que el feto depende para su subsistencia totalmente de su madre y, si su existencia pone en peligro la vida de ella $(6)^{27}$, estaría permitido entonces el aborto terapéutico en cualquiera etapa del embarazo. Sin embargo, una vez que el bebé ha asomado su cabeza o parte de su cuerpo, su vida se considera de igual valor que la de la madre y no se puede atentar contra ella.

¿Qué ocurre cuando existe la posibilidad de que el bebé pueda nacer deforme o provoque "disturbios emocionales y psicológicos serios para la madre"?

En el primero de los casos, Eisenberg señala que la mayoría de los poskim prohíben el aborto en caso de "malformaciones o anomalías encontradas en el feto. El rabino Moshé Feinstein, uno de los más importantes poskim del siglo pasado, dictamina que incluso la amniocentesis está prohibida si se realiza para evaluar únicamente los defectos de nacimiento para que los padres puedan solicitar un aborto" (6). Sin embargo, si el examen es con otra finalidad médica no hay obstáculo para realizarlo.

En casos debidamente justificados, se prevén también razones psiquiátricas para efectuar un aborto. Sin embargo, este punto es bastante discutido. Por una parte, se conocen episodios en que el embarazo puede producir depresión pre o postparto, y volver irritable a la madre hasta el punto de cometer alguna locura. Por otra, en nuestros días la depresión es una enfermedad

27 En este caso, Heisenberg señala que el feto se "considera equivalente a un rodef, un perseguidor, "que va tras la madre con la intención de matarla". Para su afirmación se basa en Maimónides, Mishne Torá, Leyes de Asesinato 1:9; Talmud Sanedrín 72b. absolutamente tratable, por lo que no justificaría una acción como esta.

Es posible, en casos muy especiales y certificados, encontrar normas que permitan el aborto antes de los 40 días de gestación y hasta un máximo de tres meses. Pero es necesario establecer con claridad que el aborto por conveniencia, economía u otra razón está prohibido desde la concepción en la ley judaica.

\section{La clonación}

Pese a lo promisorio que podrían ser sus resultados, presenta graves problemas éticos. Cada persona es producto de la combinación genética entre el óvulo y el espermatozoide; el resultado de dicha unión que ha llegado a término es un ser humano en el que se ha "recombinado" el aporte genético de ambos padres, por lo que, aun teniendo la misma materia, es diferente de sus progenitores. Ninguna persona es igual a otra(7).

En la clonación, en cambio, se busca la creación de réplicas del material clonado y en este proceso no hay ni interacción de los sexos ni recombinación genética. La clonación presenta claros problemas éticos por la manipulación genética que conlleva. No cabe duda de que podría no sólo mejorar la vida del ser humano, sino también alargar su vida y facilitar los trasplantes; pero, por otra parte, existe siempre el riesgo de una manipulación inescrupulosa.

\section{"He aqui yo pongo hoy delante de vosotros la bendición y la maldición: la bendición, si oyereis los mandamientos de Jehová vuestro Dios, que yo os prescribo hoy, y la maldición, si no oyereis los mandamientos de Jehová vuestro Dios, y os apartareis del camino que yo os ordeno hoy..." ${ }^{28}$}

El versículo que precede puede resumirse como "he aquí que delante de ti pongo la vida y la muerte, escoge la vida”. Escoger la vida significa escoger los caminos señalados por la Torá a través del cumplimiento de

28 Deuteronomio 11, 26-28a. En la versión de la Biblia de Reyna y Valera (1960) se habla de Jehová. El texto masorético hebreo no reconoce ese nombre y se usa el Tetragamatron YHVH (Yod, Hei, Vav, Hei), el nombre inefable de Dios que, cuando aparece en el texto masorético, se lee Elokim, HaShem o Adonai. 
sus preceptos, los que -explicados por los sabios del Judaísmo- han dado origen a la Halajá.

\section{A modo de conclusión}

Ciertamente, cada uno de los temas someramente aquí abordados merecen una exposición más amplia e, incluso, hay otros que no han sido incluidos para los cuales también pueden encontrarse posiciones rabínicas basadas en la Halajá.

Puede decirse que, efectivamente, la Halajá se ha visto impactada por problemas que la desafían y, seguramente, muchos otros vendrán en las décadas siguientes. Como toda normativa de vida, la Halajá deberá estar en condiciones de dar respuestas a cada uno de ellos.

Los autores consultados señalan que ante cualquier duda de tipo halájico debe necesariamente recurrirse a un rabino que conozca y se encuentre especializado en el tema, porque -como señalamos- es quien estará autorizado para emitir un juicio o fallo rabínico que no entre en contradicción con la Halajá.

No veo que los conflictos sean insolubles, pero sí que dan origen a respuestas que no necesariamente son idénticas.

Finalizo citando los dos últimos párrafos de una entrevista realizada por el periodista Jorge Rouillon(8) a los rabinos Yeshaiahu Rubinstein y Yoseph Bitton:

"En esta relación entre fe y ciencia hay muchas paradojas no resueltas, muchas dudas por investigar. La verdad revelada está en el pasado, mientras que la verdad científica está en el futuro", expresó Rubinstein.

Bitton, remitiéndose a una cita de la revista del New York Times, apuntó a una entrańable ligazón: "El científico escala la montaña de la sabiduría científica y en la cima se encuentra con el teólogo, que lo estaba esperando allí desde hace muchos años".

\section{Referencias}

1. Abraham S. The Comprehensive Guide to Medical Halachah. Jerusalem-New York: Feldheim Publishers; 1996.

2. Walter J. Euthanasia. Journal of the American Medical Ass 1980; 205: 337.

3. Stroe M. Un Médico Observante. Disponible en http://www.judaismohoy.com/article.php?article_id=157, consultado en enero 12, 2010.

4. Jacobovitz I. Los experimentos médicos con seres humanos en la legislación judía. En: Carmell A, Domb C. (eds). El desafío, la Torá frente a la ciencia y sus problemas. México: Asociación Torá Vadaat, A.C.; 1977: 459-460.

5. Rabinovitch N. ¿Qué dice la halajá respecto a los trasplantes de órganos? En: Carmell A, Domb C. (eds). El desafio, la Torá frente a la ciencia y sus problemas. México: Asociación Torá Vadaat, A.C.; 1977: 464.

6. Eisenberg D. El aborto de acuerdo a la Ley Judia. Disponible en http://www.aishlatino.com/a/cym/48419512.html, consultado en enero 12, 2010.

7. Cohen D. La clonación humana: El desafio ético del hombre moderno. Disponible en http://www.judaicasite.com/internal. php?nID=247, consultado en enero 12, 2010.

8. Judaísmo y Ciencia. Entrevista al rabino Iosef Bitton. Diario La Nación, Buenos Aires, Argentina, 20 de mayo de 1998. Disponible en http://serjudio.com/dnoam/jbitton002.htm, consultada en enero 12, 2010.

Recibido: 19 de febrero de 2010

Aceptado: 23 de marzo de 2010 